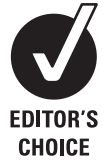

See Commentary, p 715

${ }^{1}$ Center for Human Genomics, Department of Pediatrics, Wake Forest University Health Sciences, Winston-Salem, North Carolina, USA; ${ }^{2}$ Pulmonary, Critical Care, Sleep, and Allergy Medicine Section, Department of Internal Medicine, University of Nebraska Medical Center Omaha, Nebraska, USA;

${ }^{3}$ Department of Epidemiology, College of Public Health, University of Nebraska Medical Center, Omaha, Nebraska, USA; ${ }^{4}$ Epidemiology Branch, National Institute of Environmental Health Sciences, Research Triangle

Park, North Carolina, USA:

${ }^{5}$ Occupational Epidemiology

Branch, NCl, NIH, DHHS,

Rockville, Maryland, USA

Correspondence to:

Dr Jane A Hoppin, Epidemiology Branch, NIEHS, PO Box 12233 MD A3-05, Research Triangle Park, NC 27709, USA: hoppin1@niehs.nih.gov

Accepted 7 February 2009

Published Online First

15 March 2009

\section{Rhinitis associated with pesticide exposure among commercial pesticide applicators in the Agricultural Health Study}

\author{
R E Slager, ${ }^{1} \mathrm{~J}$ A Poole, ${ }^{2}$ T D LeVan, ${ }^{2,3}$ D P Sandler, ${ }^{4}$ M C R Alavanja, ${ }^{5}$ J A Hoppin ${ }^{4}$
}

ABSTRACT

Objectives: Rhinitis is common, but the risk factors are not well described. To investigate the association between current rhinitis and pesticide use, we used data from 2245 lowa commercial pesticide applicators in the Agricultural Health Study.

Methods: Using logistic regression models adjusted for age, education and growing up on a farm, we evaluated the association between current rhinitis and 34 pesticides used in the past year.

Results: 74\% of commercial pesticide applicators reported at least one episode of rhinitis in the past year (current rhinitis). Five pesticides used in the past year were significantly positively associated with current rhinitis: the herbicides 2,4-D, glyphosate and petroleum oil, the insecticide diazinon and the fungicide benomyl. The association for 2,4-D and glyphosate was limited to individuals who used both in the past year (OR 1.42, 95\% $\mathrm{Cl} 1.14$ to 1.77). Both petroleum oil and diazinon showed consistent evidence of an association with rhinitis, based on both current use and exposure-response models. We saw no evidence of confounding by common agricultural rhinitis triggers such as handling grain or hay.

Conclusions: Exposure to pesticides may increase the risk of rhinitis.

Rhinitis is an important but often under-diagnosed disease in occupational medicine. ${ }^{12}$ Known causative agents of workplace-induced rhinitis include, in part, air pollutants, cigarette smoke, latex, psyllium, acid anhydride, platinum, toluene diisocyanate, ammonia, detergents and animals. ${ }^{12}$ Whether pesticides are important agents for upper airway symptoms, such as rhinitis, is unknown. To date, only one study has reported an association between occupational pesticide use and rhinitis. Grape farmers in Crete who used pesticides had a higher prevalence of allergic rhinitis symptoms compared to grape farmers who did not use pesticides and control subjects. ${ }^{3}$ In the Crete study, several groups of pesticides were associated with allergic rhinitis symptoms, but the strongest associations were with the bipyridyl herbicides paraquat and diquat, dithiocarbamate fungicides and carbamate insecticides.

In the United States, working with pesticides, applying pesticides to livestock and applying pesticides aerially have been associated with a higher prevalence of lower respiratory tract symptoms. ${ }^{4-6}$ An analysis from the Agricultural Health Study (AHS), a longitudinal study of licensed pesticide applicators from Iowa and North Carolina, previously found that pesticides were

\section{What this paper adds}

- Rhinitis is common but few studies have evaluated pesticide risk factors for upper respiratory symptoms.

- The prevalence of rhinitis among lowa commercial pesticide applicators was $74 \%$, much higher than general population rates of 20-30\%.

- Five pesticides were positively associated with current rhinitis.

- Diazinon and petroleum oil herbicide showed the most consistent association, while 2,4-D and glyphosate were associated with rhinitis only among those applicators who applied both pesticides.

- Exposure to pesticides may increase the risk of rhinitis, however, further research is needed to characterise the patterns of pesticide and related exposures to understand these findings.

associated with increased wheeze among commercial licensed pesticide applicators and among licensed farmer pesticide applicators. ${ }^{78}$ In the AHS commercial applicators, eight of 16 herbicides and the organophosphate insecticides terbufos, fonofos, chlorpyrifos and phorate, were significantly associated with wheeze. ${ }^{8}$ Among farmer pesticide applicators, $27 \%$ of the pesticides evaluated were significantly associated with elevated odds of wheeze, several in a dosedependent manner.' While pesticides have been associated with wheeze, a lower respiratory symptom, among pesticide applicators in the AHS, the association between upper respiratory symptoms and pesticide use has not been investigated.

The aim of this analysis was to evaluate whether pesticide use was associated with rhinitis among commercial pesticide applicators in the AHS. This AHS subgroup provided the opportunity to explore pesticide associations in a highly exposed population without other major occupational exposures that may aggravate rhinitis.

\section{METHODS}

\section{Study population}

This cross-sectional analysis of occupational rhinitis and pesticide exposure used data provided by commercial pesticide applicators in the AHS cohort. ${ }^{9}$ The AHS has been described in detail previously. ${ }^{9}$ Briefly, the AHS is a prospective study of 57311 licensed pesticide applicators (52395 
farmers and 4916 commercial applicators). The cohort was recruited between 1993 and 1997 among persons applying for certification to use restricted-use pesticides in Iowa and North Carolina. Commercial applicators are those individuals hired to apply pesticides to land, animals and seed; commercial applicators were only recruited in Iowa. ${ }^{8}$

\section{Exposure characterisation}

Pesticide exposure and rhinitis were assessed at enrolment using two self-administered questionnaires. The first, completed at enrolment, obtained detailed information on use of 22 pesticides on the market at the time of enrolment (ever use, use during the past year, frequency of use and total number of years used) and information on ever-use of 18 additional pesticides as well as smoking history, current agricultural activity and demographics. The second questionnaire, which was mailed back by the participants an average of 1 month after enrolment, obtained more detailed information about the 18 additional pesticides as well as medical history, including rhinitis, conjunctivitis, sinusitis and asthma. Questionnaires are available at www.aghealth.org/questionnaires.html.

For each specific pesticide investigated, applicators were asked to indicate if they had used it during the year before enrolment. Individuals who did not mark use in the past year were considered non-current users. We had information on the current use of 16 herbicides, 11 insecticides, five fungicides and two fumigants.

The institutional review boards of the National Institutes of Health (Bethesda, Maryland) and its contractors approved the AHS. At enrolment, the study was explained to potential participants, who indicated consent by returning questionnaires.

\section{Medical history definitions}

Our main outcome was current rhinitis, based on the applicator's answer to the question: "During the past 12 months have you had a stuffy, itchy, or runny nose?". Rhinitis severity was based on responses to the question: "How many episodes of stuffy, itchy, or runny nose have you had in the past 12 months?", for which there were five possible responses: "1 episode, 2 , episodes, 3-6 episodes, 7-12 episodes and 12 or more episodes". Sinusitis was defined as sinusitis or sinus problems in the past 12 months and conjunctivitis was defined as watery, itchy eyes in the past 12 months. People with asthma were defined as a self-report of a physician-diagnosis of asthma. A diagnosis of either hay fever or eczema was also self-reported.

Because the outcome information was on the take-home questionnaire, this analysis is limited to commercial applicators who returned both questionnaires. Only $46 \%$ of commercial pesticide applicators returned the second questionnaire, and responders were more likely to apply or handle pesticides than non-responders and less likely to engage in farming activities. However, we found no appreciable differences between responders and non-responders with regard to age, smoking or demographic factors with the exception of education where individuals with a higher education were more likely to participate.

\section{Statistical analyses}

We examined the association between pesticide use in the past year and current rhinitis using a base model controlling for potential confounders. Adjusted odds ratios (OR) were calculated from logistic regression models controlling for age (16-30, 31-40, 41-50, 51-83 years), education ( $\leqslant$ high school, $>$ high school), and growing up on a farm (self-report of having spent more than half of one's life on the farm before age 18). Covariates added to the model were assessed for goodness-of-fit by the change in -2 log likelihood. Inclusion of terms for body mass index and smoking history (never/former/current, pack-years or cigarettes per day) were not significantly associated with current rhinitis after adjustment and did not alter the pesticide associations, and therefore were not included in the base model.

We evaluated the association between individual pesticides and current rhinitis for both ever use in the past year as well as frequency of application. We limited our analysis to pesticides used by at least $1 \%$ of the population. Six of 40 pesticides (coumaphos, parathion, aldicarb, DDVP, lindane and ziram) were excluded from our analysis based on this criterion.

To model exposure-response, we used the categories of average days in the past year of applying pesticides from the questionnaire $(0,1-4,5-9,10-19,20-39,40-59,60-150$ days, more than 150 days); categories were collapsed if there were insufficient numbers of exposed individuals ( $<1 \%$ in a cell). We performed $\chi^{2}$ tests for trend for each chemical using an ordinal term for the frequency of use category. Exposure-response was not assessed for fungicides and fumigants due to small numbers of exposed individuals.

To address potential confounding by use of other pesticides we first assessed pairwise correlations between pesticides that were associated with current rhinitis. For pairs of pesticides (current use) with a Spearman correlation coefficient greater than 0.3, we constructed models including both pesticides. For pesticides that were potentially confounded by other chemicals, we built exposure-response models that contained the use status (current/no current use) of the confounder. Additionally, to analyse the strongly correlated $(r=0.7)$ current use patterns of 2,4-D and glyphosate, an additional four category variable was created: did not use either 2,4-D or glyphosate in the past year (reference category), used glyphosate but not 2,4-D (excluded current users of 2,4-D), used 2,4-D but not glyphosate (excluded current users of glyphosate), and used both. To model exposure response in the past year for these two herbicides, we created exposure-response models for each of these three mutually exclusive categories of use: used 2,4-D only, used glyphosate only, and total days used either chemical. For 2,4-D alone and glyphosate alone models, we used the questionnaire categories for the exposure-response models. For users of both 2,4-D and glyphosate, we created a summary variable of total days of either 2,4-D or glyphosate use in the past year and categorised it in quartiles (1-19 days, 20-39 days, 40-69 days or more than 70 days). The reference category for each of these three exposure-response models was non-users of both 2,4-D and glyphosate in the past year.

We conducted these analyses using the P1REL0506 release of the AHS data and SPSS software (v 13.0 for Macintosh; SPSS, Chicago, Illinois, USA).

\section{RESULTS}

We had complete information on all base model covariates for 2245 commercial applicators. Commercial applicators in the AHS are predominantly white males with a median age of 39 years at enrolment (range 16-83) (table 1). A total of 1664 individuals $(74 \%)$ reported at least one episode of current rhinitis in the past year. Individuals with current rhinitis were younger and more educated than those without current rhinitis. As anticipated, individuals with rhinitis were also more likely to report increased asthma, conjunctivitis and sinusitis. Growing up on a farm was inversely associated with current rhinitis after adjusting for the base model covariates (OR 0.79, 95\% CI 0.64 to 
0.97). Applicators in this cohort reported median use of three pesticides in the past year and the number of years of pesticide application did not differ between those with and without rhinitis. There was also no significant difference in reported use of personal protective equipment in those individuals with and without current rhinitis (data not shown). Although never smokers were more likely to report rhinitis, there was no association between smoking status and rhinitis after adjusting for base model covariates.

Current use of five of 34 pesticides was positively associated with current rhinitis (table 2). Three herbicides (2,4-D, glyphosate and petroleum oil), one organophosphate insecticide (diazinon), and one fungicide (benomyl) were significantly associated with current rhinitis. Applicators using benomyl in

Table 1 Characteristics of 2245 lowa commercial pesticide applicators in the Agricultural Health Study by rhinitis status, 1993-1997

\begin{tabular}{|c|c|c|}
\hline & $\begin{array}{l}\text { Current rhinitis* } \\
(\mathrm{n}=1664) \\
\mathrm{n}(\%)\end{array}$ & $\begin{array}{l}\text { No current rhinitis* } \\
(\mathrm{n}=581) \\
\mathrm{n}(\%)\end{array}$ \\
\hline \multicolumn{3}{|l|}{ Age (years) } \\
\hline $16-30$ & $391(24)$ & $73(13)$ \\
\hline $31-40$ & $621(37)$ & $146(25)$ \\
\hline $41-50$ & $432(26)$ & $183(31)$ \\
\hline $51-60$ & 154 (9) & $114(20)$ \\
\hline $61-83$ & $66(4)$ & $65(11)$ \\
\hline \multicolumn{3}{|l|}{ Body mass index $\left(\mathrm{kg} / \mathrm{m}^{2}\right) \dagger$} \\
\hline$<25$ & $487(30)$ & $162(28)$ \\
\hline$\geqslant 25$ & $1152(70)$ & $407(72)$ \\
\hline \multicolumn{3}{|l|}{ Sex } \\
\hline Male & $1575(95)$ & $557(96)$ \\
\hline Female & $89(5)$ & $24(4)$ \\
\hline \multicolumn{3}{|l|}{ Educational level } \\
\hline High school or less & $620(37)$ & $326(56)$ \\
\hline More than high school & $1044(63)$ & $255(44)$ \\
\hline \multicolumn{3}{|l|}{ Race } \\
\hline White & 1653 (99) & $580(99)$ \\
\hline Other & $11(0.7)$ & $1(0.2)$ \\
\hline \multicolumn{3}{|l|}{ Medical history } \\
\hline Asthma & $95(6)$ & $19(3)$ \\
\hline Conjunctivitis past year§ & $850(52)$ & $36(6)$ \\
\hline Sinusitis past year & $688(42)$ & $74(13)$ \\
\hline \multicolumn{3}{|l|}{ Smoking status $\dagger$} \\
\hline Never smoker & $827(50)$ & $253(44)$ \\
\hline Past smoker & $477(29)$ & $188(32)$ \\
\hline Current smoker & $357(21)$ & $139(24)$ \\
\hline Grew up on a farm** & $1032(62)$ & $410(71)$ \\
\hline $\begin{array}{l}\text { Currently living or working on a } \\
\text { farm† }\end{array}$ & $521(31)$ & $186(32)$ \\
\hline \multicolumn{3}{|l|}{ Lifetime application of pesticides $\dagger$} \\
\hline None & $70(4)$ & $28(5)$ \\
\hline 1 year or less & $114(7)$ & $42(8)$ \\
\hline $2-5$ years & $411(26)$ & $123(23)$ \\
\hline $6-10$ years & $344(22)$ & $113(21)$ \\
\hline $11-20$ years & $448(28)$ & $137(25)$ \\
\hline$>20$ years & $210(13)$ & $98(18)$ \\
\hline
\end{tabular}

*Current rhinitis defined as yes to "During the past 12 months have you had a stuffy, itchy, or runny nose?".

† Numbers and percentages reflect data missing.

$\$$ Asthma defined as yes to "Ever diagnosed with asthma or reactive lung disease?"; information was missing for 4 individuals.

$\S$ Conjunctivitis defined as yes to "During the past 12 months have you had a watery, itchy eyes?"; information was missing for 25 individuals.

- Sinusitis defined as yes to "During the past 12 months have you had sinusitis or sinus problems?"; information was missing for 54 individuals.

${ }^{* *}$ Grew up on a farm defined as yes to "Before age 18, did you live at least half of your life on a farm?". the past year had the highest odds of current rhinitis (OR 2.35, 95\% CI 1.11 to 4.98). Current use of carbofuran was inversely associated with current rhinitis (OR $0.65,95 \%$ CI 0.43 to 0.98 ).

We evaluated exposure-response trends for 25 of the 34 pesticides. Table 3 presents results for the pesticides that were significantly associated with rhinitis in table 2 in current use models, as well as other chemicals previously reported to be associated with wheeze (chlorimuron-ethyl) ${ }^{8}$ or rhinitis (paraquat), ${ }^{3}$ and chemicals with a $p$ trend value of $\sim 0.1$ (carbaryl and dicamba) in the present analysis. While we observed significant exposure-response trends for four pesticides in current use models (petroleum oil, diazinon and use of both glyphosate and 2,4-D), few exposure-response trends were monotonic (table 3). For example, the OR associated with 20-39 days of use of petroleum oil herbicide was 2.31 (95\% CI 1.1 to 4.59 ), but use for 40 or more days per year had an odds ratio of 1.28 (95\% CI 0.73 to 2.24$)$. Use of carbofuran for less than 5 days in the past year $\left(\mathrm{OR}_{1-4}\right.$ days 0.33 , $95 \%$ CI 0.15 to 0.72 ) was inversely associated with rhinitis, however there were relatively few applicators in this category $(1 \%$ of cases and $2 \%$ of controls). Increased use of carbofuran was positively associated with rhinitis $\left(\mathrm{OR}_{20}\right.$ or more days 1.50$)$, although the association was not significant. The association with 2,4-D and glyphosate was limited to those who used both in the past year; individuals who were in the highest category of 2,4-D and glyphosate use had the highest OR (1.55, 95\% CI 1.08 to 2.24$)$ of all 2,4-D and glyphosate users.

We conducted a number of sensitivity analyses to assess the robustness of our findings. First, we evaluated the role of correlated pesticides as an explanation for our findings. For the pesticides that were significant in either the current use (table 2) or exposure-response models (table 3), we evaluated the correlation between pesticides to address potential confounding. Seven pairs of pesticides had Spearman correlation coefficients greater than 0.3. There was some evidence of attenuation of the associations, especially between the herbicides. However, the odds ratio for petroleum did not change significantly in pairwise models with correlated herbicides. Further exploration of the correlation between glyphosate and 2,4-D ( $r=0.7)$ demonstrated that rhinitis was associated only with current use of both chemicals ( $\mathrm{OR}_{\text {both }} 1.42,95 \%$ CI 1.14 to 1.77$)$, whereas current use of either glyphosate alone ( $\mathrm{OR}_{\text {glyphosate }} 1.07,95 \%$ CI 0.78 to 1.48$)$ or 2,4-D alone $\left(\mathrm{OR}_{2,4-\mathrm{D}} 0.99,95 \%\right.$ CI 0.63 to 1.54$)$ was not significantly associated with rhinitis when both were modelled together. Furthermore, a significant exposure-response trend was observed only when the model was restricted to users of both glyphosate and 2,4-D (table 3).

Next, we assessed whether the choice of comparison group influenced results. When we limited the comparison group to never users of a particular pesticide (thereby excluding former users who may have removed themselves from pesticide exposure after experiencing nasal symptoms as well as those who no longer used the chemical for other reasons), the OR increased and the exposure-outcome relationship became stronger. For example, the OR for diazinon increased from 1.84 to 1.91 (95\% CI 1.27 to 2.88). Alachlor (OR $1.36,95 \%$ CI 1.02 to 1.80 ), malathion (OR $1.49,95 \%$ CI 1.10 to 2.00 ) and the fumigant aluminium phosphide (OR 1.66, 95\% CI 1.03 to 2.67 ) were the only pesticides that reached statistical significance using this more restricted comparison group. We repeated analyses excluding those individuals with only one or two episodes of rhinitis in the past year. For most pesticides, the odds ratios were similar to those with the broader outcome definition, but associations for two pesticides became statistically significant. The OR for pendimethalin increased from 1.25 
Table 2 Odds of current rhinitis associated with use of 34 pesticides among 2245 commercial pesticide applicators in the Agricultural Health Study

\begin{tabular}{|c|c|c|c|}
\hline & $\begin{array}{l}\text { Current rhinitis } \\
\text { ( } \mathrm{n}=1664), \\
n \text { (\% exposed) }\end{array}$ & $\begin{array}{l}\text { No current rhinitis } \\
(\mathrm{n}=581) \text {, } \\
\mathrm{n} \text { (\% exposed) }\end{array}$ & $\mathrm{OR}^{*}(95 \% \mathrm{Cl})$ \\
\hline \multicolumn{4}{|l|}{ Herbicides } \\
\hline $2,4-D$ & $750(45)$ & $217(37)$ & 1.34 (1.09 to 1.64$)$ \\
\hline Alachlor & $316(19)$ & $90(16)$ & $1.26(0.96$ to 1.64$)$ \\
\hline Atrazine & $450(27)$ & $145(25)$ & $1.09(0.86$ to 1.36$)$ \\
\hline Butylate & $69(4)$ & $19(3)$ & 1.30 (0.76 to 2.22$)$ \\
\hline Chlorimuron-ethyl & $410(25)$ & $124(21)$ & $1.18(0.93$ to 1.50$)$ \\
\hline Cyanazine & $364(22)$ & $124(22)$ & 1.04 (0.81 to 1.32$)$ \\
\hline Dicamba & $568(35)$ & $165(29)$ & $1.18(0.95$ to 1.47$)$ \\
\hline EPTC & $231(14)$ & $71(13)$ & 1.17 (0.87 to 1.58$)$ \\
\hline Glyphosate & $869(52)$ & $252(44)$ & $1.32(1.08$ to 1.61$)$ \\
\hline Imazethapyr & $449(28)$ & $152(27)$ & 1.05 (0.84 to 1.32$)$ \\
\hline Metolachlor & 434 (27) & $145(26)$ & 1.05 (0.83 to 1.32$)$ \\
\hline Metribuzin & $270(16)$ & $80(14)$ & $1.17(0.89$ to 1.55$)$ \\
\hline Paraquat & $117(7)$ & $31(5)$ & 1.32 (0.86 to 2.01$)$ \\
\hline Pendimethalin & $453(27)$ & $125(22)$ & $1.25(0.99$ to 1.59$)$ \\
\hline Petroleum oil & $243(15)$ & $50(9)$ & 1.74 (1.25 to 2.42$)$ \\
\hline Trifluralin & $398(25)$ & $124(22)$ & $1.14(0.90$ to 1.45$)$ \\
\hline \multicolumn{4}{|l|}{ Insecticides } \\
\hline \multicolumn{4}{|l|}{ Organophosphates } \\
\hline Chlorpyrifos & $259(16)$ & $70(12)$ & 1.29 (0.96 to 1.73$)$ \\
\hline Diazinon & $185(11)$ & $31(5)$ & 1.84 (1.23 to 2.75$)$ \\
\hline Fonofos & $63(4)$ & $27(5)$ & 0.80 (0.49 to 1.29$)$ \\
\hline Malathion & $288(17)$ & $78(14)$ & $1.28(0.96$ to 1.69$)$ \\
\hline Phorate & $62(4)$ & $14(2)$ & $1.74(0.95$ to 3.20$)$ \\
\hline Terbufos & $111(7)$ & $31(6)$ & $1.26(0.82$ to 1.92$)$ \\
\hline Trichlorfon & $54(3)$ & $8(1)$ & 2.01 (0.93 to 4.35$)$ \\
\hline \multicolumn{4}{|l|}{ Carbamates } \\
\hline Carbaryl & $192(12)$ & $47(8)$ & 1.29 (0.91 to 1.82$)$ \\
\hline Carbofuran & $77(5)$ & $39(7)$ & 0.65 (0.43 to 0.98$)$ \\
\hline \multicolumn{4}{|l|}{ Pyrethroids } \\
\hline Permethrin (crops) & $206(13)$ & $63(11)$ & $1.08(0.79$ to 1.47$)$ \\
\hline Permethrin (animals) & $47(3)$ & $8(1)$ & 1.91 (0.88 to 4.13$)$ \\
\hline \multicolumn{4}{|l|}{ Fungicides } \\
\hline Benomyl & $67(4)$ & $8(1)$ & 2.35 (1.11 to 4.98$)$ \\
\hline Captan & $44(3)$ & $10(2)$ & $1.23(0.60$ to 2.51$)$ \\
\hline Chlorothalonil & $110(7)$ & $26(5)$ & 1.33 (0.84 to 2.09$)$ \\
\hline Maneb/Macozeb & $33(2)$ & $7(1)$ & 1.09 (0.47 to 2.52$)$ \\
\hline Metalaxyl & $68(4)$ & $15(3)$ & 1.30 (0.72 to 2.33$)$ \\
\hline \multicolumn{4}{|l|}{ Fumigants } \\
\hline Aluminium phosphide & $102(6)$ & $23(4)$ & 1.60 (0.99 to 2.57$)$ \\
\hline Methyl bromide & $20(1)$ & $6(1)$ & $1.04(0.40$ to 2.66$)$ \\
\hline
\end{tabular}

to 1.31 (95\% CI 1.01 to 1.69$)$ and the OR for phorate increased from 1.74 to 1.98 (95\% CI 1.04 to 3.78$)$. When we excluded subjects with asthma ( $6 \%$ of cases and $3 \%$ of controls), we saw no difference in the overall pesticide results (data not shown). When we stratified our results based on hay fever or eczema status, significant pesticide associations were almost exclusively in the group never diagnosed with either condition; however, we had limited power to assess rhinitis among those with hay fever or eczema (data not shown).

As some of the commercial pesticide applicators also participated in a variety of farm-related activities, we investigated other agricultural and animal exposures as potential confounders of pesticide exposure and current rhinitis associations. As shown in table 4 , activities that were significantly associated with current rhinitis were butchering animals, repairing engines, welding and painting. Neither handling stored hay (OR 1.18, 95\% CI 0.92 to
1.51) nor handling stored grain (OR $1.19,95 \%$ CI 0.97 to 1.47 ) was associated with rhinitis. When the farming tasks that were significantly associated with rhinitis were included in pairwise models with significant pesticides, there was no attenuation of either the farming or pesticide associations (data not shown).

\section{DISCUSSION}

These results support the role of occupational pesticide exposure in rhinitis. Our findings are not explained by common agricultural exposures, such as hay, and are consistent with and expand on previous findings of rhinitis symptoms among pesticide applicators. Current use of five of 34 pesticides was positively associated with rhinitis and four of these pesticides had significant exposure-response trends. Half of the pesticides associated with rhinitis in the current use analysis were herbicides, however these associations were attenuated after 
Table 3 Exposure-response models for selected pesticides used in the past year among commercial pesticide applicators in the Agricultural Health Study, 1993-1997

\begin{tabular}{|c|c|c|c|c|}
\hline Chemical & $\begin{array}{l}\text { Current rhinitis } \\
\text { ( } n=1664) \\
n \text { ( } \% \text { exposed) }\end{array}$ & $\begin{array}{l}\text { No current rhinitis } \\
\text { ( } \mathrm{n}=581) \text {, } \\
\mathrm{n} \text { (\% exposed) }\end{array}$ & $0 R^{*}(95 \% \mathrm{Cl})$ & p Trend \\
\hline \multicolumn{5}{|l|}{ Days/year applied $\dagger$} \\
\hline \multicolumn{5}{|l|}{ Insecticides } \\
\hline \multicolumn{5}{|l|}{ Carbaryl } \\
\hline 0 & 1547 (88) & 527 (92) & 1.00 & \multirow[t]{5}{*}{0.133} \\
\hline $1-4$ & $69(4)$ & $19(3)$ & 1.09 (0.64 to 1.86$)$ & \\
\hline $5-9$ & $51(3)$ & $10(2)$ & $1.51(0.75$ to 3.06$)$ & \\
\hline $10-19$ & $32(2)$ & $10(2)$ & 1.03 (0.49 to 2.17$)$ & \\
\hline 20 or more & $39(2)$ & $8(1)$ & $1.74(0.79$ to 3.80$)$ & \\
\hline Carbofuran & & & & 0.761 \\
\hline 0 & 1538 (95) & $516(93)$ & 1.00 & \\
\hline $1-4$ & $16(1)$ & $13(2)$ & 0.33 (0.15 to 0.72 ) & \\
\hline $5-19$ & $36(2)$ & $18(3)$ & 0.69 (0.38 to 1.24$)$ & \\
\hline 20 or more & $24(2)$ & $6(1)$ & 1.50 (0.59 to 3.81$)$ & \\
\hline \multicolumn{5}{|l|}{ Diazinon } \\
\hline 0 & 1461 (89) & $539(95)$ & 1.00 & \multirow[t]{4}{*}{0.026} \\
\hline $1-4$ & $76(5)$ & $11(2)$ & 2.21 (1.15 to 4.27$)$ & \\
\hline $5-9$ & $38(2)$ & $8(1)$ & $1.16(0.53$ to 2.55$)$ & \\
\hline 10 or more & $68(4)$ & $12(2)$ & 1.88 (0.99 to 3.55$)$ & \\
\hline \multicolumn{5}{|l|}{ Herbicides } \\
\hline \multicolumn{5}{|l|}{ Chlorimuron-ethyl } \\
\hline 0 & $1240(75)$ & $449(79)$ & 1.00 & \multirow[t]{6}{*}{0.335} \\
\hline $1-4$ & $39(2)$ & $14(2)$ & 0.89 (0.47 to 1.70$)$ & \\
\hline $5-9$ & $62(4)$ & $17(3)$ & 1.20 (0.68 to 2.12$)$ & \\
\hline $10-19$ & $136(8)$ & $38(7)$ & 1.45 (0.98 to 2.15$)$ & \\
\hline $20-39$ & $128(8)$ & $38(7)$ & 1.12 (0.76 to 1.66$)$ & \\
\hline 40 or more & $45(3)$ & $16(3)$ & 1.05 (0.58 to 1.92$)$ & \\
\hline \multicolumn{5}{|l|}{ Dicamba } \\
\hline 0 & $1062(65)$ & $395(71)$ & 1.00 & \multirow[t]{7}{*}{0.189} \\
\hline $1-4$ & $78(5)$ & $20(4)$ & $1.40(0.83$ to 2.36$)$ & \\
\hline $5-9$ & $103(6)$ & $32(6)$ & 1.05 (0.68 to 1.61$)$ & \\
\hline $10-19$ & $150(9)$ & $43(8)$ & $1.14(0.79$ to 1.65$)$ & \\
\hline $20-39$ & $133(8)$ & $46(8)$ & $1.03(0.71$ to 1.49$)$ & \\
\hline $40-59$ & $51(3)$ & $11(2)$ & $1.66(0.84$ to 3.27$)$ & \\
\hline 60 or more & $49(3)$ & $12(2)$ & $1.36(0.70$ to 2.64$)$ & \\
\hline \multicolumn{5}{|l|}{ Paraquat } \\
\hline 0 & 1534 (93) & $540(95)$ & 1.00 & \multirow[t]{4}{*}{0.207} \\
\hline $1-4$ & $36(2)$ & $9(2)$ & 1.29 (0.60 to 2.77$)$ & \\
\hline $5-9$ & $24(1)$ & $6(1)$ & $1.37(0.54$ to 3.50$)$ & \\
\hline 10 or more & $56(3)$ & $15(3)$ & $1.38(0.76$ to 2.50$)$ & \\
\hline \multicolumn{5}{|l|}{ Petroleum oil } \\
\hline 0 & $1398(85)$ & $518(91)$ & 1.00 & \multirow[t]{5}{*}{0.029} \\
\hline $1-9$ & $60(4)$ & $10(2)$ & $1.90(0.95$ to 3.80$)$ & \\
\hline $10-19$ & $60(4)$ & $12(2)$ & $1.79(0.94$ to 3.43$)$ & \\
\hline $20-39$ & $67(4)$ & $10(2)$ & 2.31 (1.16 to 4.59$)$ & \\
\hline 40 or more & $56(3)$ & $18(3)$ & $1.28(0.73$ to 2.24$)$ & \\
\hline \multicolumn{5}{|c|}{ 2,4-D and glyphosate: } \\
\hline \multicolumn{5}{|l|}{ 2,4-D only } \\
\hline 0 & $716(90)$ & $294(89)$ & 1.00 & 0.417 \\
\hline $1-9$ & $38(5)$ & $12(4)$ & 1.33 (0.67 to 2.67 ) & \\
\hline $10-19$ & $18(2)$ & $9(3)$ & $0.67(0.29$ to 1.57$)$ & \\
\hline $20-59$ & $11(1)$ & $7(2)$ & 0.92 (0.34 to 2.49 ) & \\
\hline 60 or more & $11(1)$ & $7(2)$ & $0.69(0.25$ to 1.89$)$ & \\
\hline Glyphosate on & & & & \\
\hline 0 & $716(78)$ & $294(81)$ & 1.00 & 0.735 \\
\hline $1-4$ & $80(9)$ & $26(7)$ & $1.27(0.78$ to 2.10$)$ & \\
\hline $5-9$ & $47(5)$ & $18(5)$ & 0.83 (0.46 to 1.49 ) & \\
\hline $10-19$ & $41(5)$ & $15(4)$ & $0.99(0.53$ to 1.86$)$ & \\
\hline $20-39$ & $17(2)$ & $7(2)$ & 0.97 (0.38 to 2.48 ) & \\
\hline 40 or more & $13(1)$ & $4(1)$ & $1.52(0.47$ to 4.90$)$ & \\
\hline
\end{tabular}


Table 3 Continued

\begin{tabular}{|c|c|c|c|c|}
\hline Chemical & $\begin{array}{l}\text { Current rhinitis } \\
\text { (n=1664), } \\
\text { n (\% exposed) }\end{array}$ & $\begin{array}{l}\text { No current rhinitis } \\
(\mathrm{n}=581) \\
\mathrm{n}(\% \text { exposed })\end{array}$ & $O R^{*}(95 \% \mathrm{Cl})$ & p Trend \\
\hline \multicolumn{5}{|c|}{ Both 2,4-D and glyphosate } \\
\hline 0 & $716(52)$ & $294(62)$ & 1.00 & \multirow[t]{5}{*}{0.009} \\
\hline $1-19$ & $162(12)$ & $43(9)$ & $1.47(1.01$ to 2.14$)$ & \\
\hline $20-39$ & $161(12)$ & $46(10)$ & 1.32 (0.92 to 1.91$)$ & \\
\hline $40-69$ & $166(12)$ & $47(10)$ & $1.42(0.98$ to 2.04$)$ & \\
\hline 70 or more & $177(13)$ & 44 (9) & 1.55 (1.08 to 2.24$)$ & \\
\hline
\end{tabular}

taking into account use of other pesticides. Glyphosate and 2,4$\mathrm{D}$ were the most highly correlated and rhinitis was associated only with current use of both herbicides. While benomyl had the highest OR (2.35) in association with rhinitis, this fungicide is used infrequently ( $3 \%$ of applicators) and we had limited power to assess exposure-response. Overall, the most consistent associations with rhinitis were with petroleum oil and the organophosphate insecticide diazinon. Based on current use and exposure-response modelling, these associations were not confounded by use of other pesticides.

Some of the chemicals identified here have been previously associated with rhinitis and lower respiratory symptoms in pesticide applicators. ${ }^{378}$ In the report on grape farmers, the herbicides paraquat and diquat were associated with allergic rhinitis, as was the herbicide glyphosate. ${ }^{3}$ In our analysis, paraquat was of borderline significance (OR 1.32, 95\% CI 0.86 to 2.01). Regional differences in pesticide usage patterns likely contributed to these observed differences. In the analysis of wheeze among commercial applicators in the AHS, 13 of 36 pesticides were significantly associated with wheeze. ${ }^{8}$ Of these 13, only two (glyphosate and petroleum oil) were associated with current rhinitis, suggesting that these chemicals may be important contributors to both upper and lower respiratory tract symptoms.

Exposure to pesticides may contribute to rhinitis by a number of mechanisms. It is well-recognised that organophosphates

Table 4 Odds ratios for current rhinitis and current farm-related exposures among 2245 commercial pesticide applicators in the Agricultural Health Study

\begin{tabular}{|c|c|c|c|}
\hline Exposure & $\begin{array}{l}\text { Current rhinitis } \\
\text { (n= 1664), } \\
\text { n (\% exposed) }\end{array}$ & $\begin{array}{l}\text { No current rhinitis } \\
\text { ( } n=581), \\
\text { n ( } \% \text { exposed) }\end{array}$ & $\mathrm{OR}^{*}(95 \% \mathrm{Cl})$ \\
\hline \multicolumn{4}{|l|}{ Animal exposures } \\
\hline Working in swine areas & $262(16)$ & $70(12)$ & $1.23(0.91$ to 1.66$)$ \\
\hline Working in poultry areas & $39(2)$ & $9(2)$ & $1.57(0.74$ to 3.34$)$ \\
\hline Beef cattle & $195(12)$ & $66(11)$ & $1.00(0.73$ to 1.38$)$ \\
\hline Dairy cattle & $32(2)$ & $8(1)$ & $1.28(0.57$ to 2.88$)$ \\
\hline Hogs & $191(12)$ & $59(10)$ & 1.07 (0.77 to 1.49$)$ \\
\hline Sheep & $41(3)$ & $11(2)$ & 1.30 (0.65 to 2.59$)$ \\
\hline Butchering animals & $235(14)$ & $45(8)$ & 1.77 (1.25 to 2.49$)$ \\
\hline Veterinary services & $269(16)$ & $84(15)$ & $1.11(0.84$ to 1.48$)$ \\
\hline \multicolumn{4}{|l|}{ Grain exposures } \\
\hline Handling stored grain & $745(45)$ & $235(40)$ & $1.19(0.97$ to 1.47$)$ \\
\hline Handling stored hay & $434(26)$ & $121(21)$ & $1.18(0.92$ to 1.51$)$ \\
\hline Grinding animal feed & $370(22)$ & $113(19)$ & $1.14(0.88$ to 1.47$)$ \\
\hline Loading or unloading silage & $136(8)$ & $41(7)$ & $1.04(0.71$ to 1.52$)$ \\
\hline \multicolumn{4}{|l|}{ Corn production } \\
\hline Field corn & $369(22)$ & $131(23)$ & $0.99(0.77$ to 1.26$)$ \\
\hline Seed corn & $38(2)$ & $15(3)$ & $0.83(0.44$ to 1.55$)$ \\
\hline Sweet corn & $70(4)$ & $15(3)$ & $1.55(0.87$ to 2.78$)$ \\
\hline Popcorn & $19(1)$ & $8(1)$ & $0.82(0.35$ to 1.93$)$ \\
\hline \multicolumn{4}{|l|}{ Other crops } \\
\hline Alfalfa & $145(9)$ & $39(7)$ & $1.35(0.92$ to 1.98$)$ \\
\hline Hay & $164(10)$ & $45(8)$ & $1.34(0.93$ to 1.93$)$ \\
\hline Oats & $122(7)$ & $33(6)$ & $1.25(0.83$ to 1.90$)$ \\
\hline Soybeans & $318(19)$ & $123(21)$ & $0.89(0.69$ to 1.14$)$ \\
\hline \multicolumn{4}{|l|}{ Maintenance activities } \\
\hline Repairing engines & $710(43)$ & $200(34)$ & $1.30(1.06$ to 1.60$)$ \\
\hline Welding & $898(54)$ & $258(44)$ & 1.39 (1.14 to 1.71$)$ \\
\hline Painting & $1205(72)$ & $348(60)$ & 1.56 (1.27 to 1.92$)$ \\
\hline Replacing asbestos brake linings & $232(14)$ & $66(11)$ & $1.26(0.93$ to 1.70$)$ \\
\hline
\end{tabular}

${ }^{*} 0$ dds ratios were adjusted for age, education status and growing up on a farm. 
inhibit the enzyme acetylcholinesterase, leading to an accumulation of acetylcholine. Cholinergic stimulation of the nasal mucosa results in increased nasal lavage secretions and subjective nasal congestion..$^{10}$ We speculate that repetitive exposure to organophosphate pesticides may cause an exaggerated nasal glandular response resulting in increased rhinitis. However, evidence for this hypothesis would be stronger if more than one of the seven organophosphates were significantly associated with rhinitis. Petroleum oil is another pesticide that was associated with rhinitis and has previously been associated with wheeze. Although knowledge of its health effects as a pesticide are limited, it is recognised that exposure to mineral and petroleum oil in metal workers results in respiratory symptoms. ${ }^{11}{ }^{12}$ Studies in animals showed that high levels of hydrocarbon oils exert toxic effects on the lung, ${ }^{13}$ but evaluation of nasal epithelium did not reveal differences. Glyphosate is a commonly used herbicide with low overall toxicity and there is little information on its impact on upper and lower respiratory symptoms. In our models, rhinitis was only associated with use of both glyphosate and 2,4-D. It remains to be determined whether a synergistic effect occurs in the upper airway with use of glyphosate and 2,4-D.

Rhinitis by definition is a subjective measure. A number of papers have assessed rhinitis as an outcome, but all have used different measures such as allergic rhinitis or doctor's diagnosis of rhinitis. Our rhinitis prevalence of $74 \%$ is higher than among Cretan grape farmers $(51 \%)^{3}$ and US and European general populations (20-30\%). ${ }^{14}{ }^{15}$ Our definition did not exclude those with colds and flu as we lacked data on rhinitis without colds or flu, so our estimates of rhinitis may be higher due to the inclusion of colds. Regardless, our results do not appear influenced by our definition, as the pesticide results are similar when we exclude individuals with one or two episodes of rhinitis (which may be attributed to a cold or flu) from our case group, leading us to conclude that pesticide use was predominantly associated with elevated odds of any rhinitis, not necessarily increased episodes.

Rhinitis in the occupational environment is recognised as a heterogeneous group of inflammatory conditions caused by exposure to airborne irritants and sensitisers. ${ }^{16}$ Although rhinitis may not be considered debilitating, these troublesome symptoms may lead to changes in behaviour, such as reduction in pesticide application. Several of our pesticide exposure-response models, for example, petroleum oil and diazinon, were not linear. The highest odds of rhinitis were in a mid-use category, which may be consistent with applicators removing themselves from repeated exposures which trigger nasal symptoms, the socalled healthy worker effect. Consistent with this healthy worker effect, Riu et al found that the first 9 months of employment are crucial for the onset of rhinitis and that longer duration of exposure was associated with a decreased risk of rhinitis. ${ }^{17}$ Additionally, we did not have temporal information in this cross-sectional study and cannot determine whether pesticide exposure occurred prior to rhinitis symptoms.

The major strength of this study is the large sample size with good information on lifetime and current pesticide use. We relied on self-report of pesticide usage, but exposure variables from the AHS have been extensively verified and have been shown to be highly reproducible in farmers. ${ }^{18}{ }^{19}$ While our study is limited by the response rate of the commercial applicators to the take-home questionnaire (46\%), the individuals who did complete the take-home questionnaire were more likely to apply pesticides more often but less likely to engage in some common agricultural activities (veterinary services, handling stored hay and grain), thus providing an opportunity to assess rhinitis in a pesticide-exposed population. Responders were similar to non-responders with regard to specific pesticide use; however, our sample was more likely to have completed high school. As educational attainment was associated with rhinitis, our sample may over-represent individuals with rhinitis.

Pesticides are commonly used in a variety of settings and very little is known about their role in upper airway symptoms. Our study of 2245 commercial pesticide applicators is the largest study to date to explore this topic. With our reliable pesticide use information, as well as good data on confounders and other agricultural exposures, we identified specific chemical agents which were associated with current rhinitis. While our study is limited by its ability to distinguish allergic from non-allergic symptoms and to establish temporality between exposure and symptoms, it suggests that use of petroleum oil herbicide and some organophosphate insecticides may contribute to upper airway symptoms.

Acknowledgements: The authors would like to thank Debra J Romberger and Susanna Von Essen for valuable support, Stuart Long for preparation of the AHS dataset and Lisa Chudomelka for formatting the manuscript. This work was supported in part by the American Academy of Allergy Asthma and Immunology Strategic Training in Allergy Research program (RES).

Funding: This work was supported by intramural research funds from the National Cancer Institute and the National Institute of Environmental Health Sciences, National Institutes of Health, US Department of Health and Human Services. RES was supported by a National Institute of Alcohol Abuse and Alcoholism R01 to principal investigator Joseph H Sisson, MD at the University of Nebraska Medical Center.

\section{Competing interests: None.}

The institutional review boards of the National Institutes of Health (Bethesda, Maryland) and its contractors approved the Agricultural Health Study.

Provenance and peer review: Not commissioned; externally peer reviewed.

\section{REFERENCES}

1. Gautrin D, Desrosiers M, Castano R. Occupational rhinitis. Curr Opin Allergy Clin Immunol 2006;6:77-84.

2. Slavin RG. Occupational rhinitis. Ann Allergy Asthma Immunol 2003:90(5 Suppl 2):2-6.

3. Chatzi L, Alegakis A, Tzanakis N, et al. Association of allergic rhinitis with pesticides use among grape farmers in Crete, Greece. Occup Environ Med 2007;64:417-21.

4. Jones SM, Burks AW, Spencer HJ, et al. Occupational asthma symptoms and respiratory function among aerial pesticide applicators. Am J Ind Med 2003;43:407-17.

5. Sprince NL, Lewis MO, Whitten PS, et al. Respiratory symptoms: associations with pesticides, silos, and animal confinement in the lowa Farm Family Health and Hazard Surveillance Project. Am J Ind Med 2000;38:455-62.

6. Wilkins JR 3rd, Engelhardt HL, Rublaitus SM, et al. Prevalence of chronic respiratory symptoms among Ohio cash grain farmers. Am J Ind Med 1999;35:150-63.

7. Hoppin JA, Umbach DM, London SJ, et al. Chemical predictors of wheeze among farmer pesticide applicators in the Agricultural Health Study. Am J Respir Crit Care Med 2002;165:683-9

8. Hoppin JA, Umbach DM, London SJ, et al. Pesticides associated with wheeze among commercial pesticide applicators in the Agricultural Health Study. Am J Epidemiol 2006;163:1129-37.

9. Alavanja MC, Sandler DP, McMaster SB, et al. The Agricultural Health Study. Environ Health Perspect 1996; 104:362-9.

10. White MV. Nasal cholinergic hyperresponsiveness in atopic subjects studied out of season. J Allergy Clin Immunol 1993:92:278-87.

11. Bukowski JA. Review of respiratory morbidity from occupational exposure to oil mists. App/ Occup Environ Hyg 2003;18:828-37.

12. Skyberg K, Ronneberg A, Christensen CC, et al. Lung function and radiographic signs of pulmonary fibrosis in oil exposed workers in a cable manufacturing company: a follow up study. Br J Ind Med 1992;49:309-15.

13. Skyberg K, Skaug V, Gylseth B, et al. Subacute inhalation toxicity of mineral oils, C15-C20 alkylbenzenes, and polybutene in male rats. Environ Res 1990;53:48-61.

14. Nathan RA. The burden of allergic rhinitis. Allergy Asthma Proc 2007;28:3-9

15. Radon K, Gerhardinger U, Schulze A, et al. Occupation and adult-onset of rhinitis in the general population. Occup Environ Med 2008;65:38-43.

16. Hellgren J, Karlsson G, Toren K. The dilemma of occupational rhinitis: management options. Am J Respir Med 2003;2:333-41.

17. Riu E, Dressel H, Windstetter D, et al. First months of employment and new onset of rhinitis in adolescents. Eur Respir J 2007;30:549-55.

18. Blair A, Tarone R, Sandler D, et al. Reliability of reporting on life-style and agricultural factors by a sample of participants in the Agricultural Health Study from lowa. Epidemiology 2002;13:94-9.

19. Hoppin JA, Yucel F, Dosemeci M, et al. Accuracy of self-reported pesticide use duration information from licensed pesticide applicators in the Agricultural Health Study. J Expo Anal Environ Epidemiol 2002;12:313-18. 